\title{
THE SPECTRUM PROBLEM FOR THE CONNECTED CUBIC GRAPHS OF ORDER 10
}

\author{
Peter Adams \\ University of Queensland, QLD 4072, Australia \\ e-mail: p.adams@uq.edu.au \\ SAAD I. EL-ZANATI \\ Illinois State University \\ Normal, IL 61790-4520 USA \\ e-mail: saad@ilstu.edu \\ UĞUR ODABAŞI \\ Istanbul University, Istanbul, 34320, Turkey \\ e-mail: ugur.odabasi@istanbul.edu.tr \\ AND

\section{WANNASIRI WANNASIT} \\ Center of Excellence in Mathematics and Applied Mathematics \\ Chiang Mai University, Chiang Mai 50200, Thailand \\ e-mail: wannasiri.w@cmu.ac.th
}

\begin{abstract}
We show that if $G$ is a connected cubic graph of order 10, then there exists a $G$-decomposition of $K_{v}$ if and only if $v \equiv 1$ or $10(\bmod 15)$ except when $v=10$ and $G$ is one of 5 specific graphs.
\end{abstract}

Keywords: spectrum problem, graph decomposition, cubic graphs.

2010 Mathematics Subject Classification: 05C51, 05C70.

\section{REFERENCES}

[1] P. Adams and D. Bryant, The spectrum problem for the Petersen graph, J. Graph Theory 22 (1996) 175-180.

https://doi.org/10.1002/(SICI)1097-0118(199606)22:2¡175::AID-JGT8¿3.0.CO;2-K 
[2] P. Adams, D. Bryant and M. Buchanan, A survey on the existence of $G$-designs, J. Combin. Des. 16 (2008) 373-410. https://doi.org/10.1002/jcd.20170

[3] P. Adams, D. Bryant and A. Khodkar, Uniform 3-factorisations of $K_{10}$, Congr. Numer. 127 (1997) 23-32.

[4] P. Adams, C. Chan, S.I. El-Zanati, E. Holdaway, U. Odabaşı and J. Ward, The spectrum problem for 3 of the cubic graphs of order 10, J. Combin. Math. Combin. Comput., to appear.

[5] P. Adams, S.I. El-Zanati and W. Wannasit, The spectrum problem for the cubic graphs of order 8, Ars Combin. 137 (2018) 345-354.

[6] B. Alspach and H. Gavlas, Cycle decompositions of $K_{n}$ and $K_{n}-I$, J. Combin. Theory Ser. B 81 (2001) 77-99. https://doi.org/10.1006/jctb.2000.1996

[7] D. Bryant and S.I. El-Zanati, Graph decompositions, in: Handbook of Combinatorial Designs, C.J. Colbourn and J.H. Dinitz (Ed(s)), 2nd Ed. (Chapman \& Hall/CRC, Boca Raton, 2007) 477-485.

[8] D.E. Bryant and T.A. McCourt, Existence results for G-designs. http://wiki.smp.uq.edu.au/G-designs/

[9] J.E. Carter, Designs on Cubic Multigraphs, Ph.D. Thesis (McMaster University, Hamilton, 1989).

[10] C.J. Colbourn and J.H. Dinitz, Handbook of Combinatorial Designs (Chapman/CRC Press, Boca Raton, 2007).

[11] G. Ge, Group divisible designs, in: Handbook of Combinatorial Designs, C.J. Colbourn and J.H. Dinitz (Ed(s)), 2nd Ed. (Chapman \& Hall/CRC, Boca Raton, 2007) 255-260.

[12] R.K. Guy and L.W. Beineke, The coarseness of the complete graph, Canad. J. Math. 20 (1968) 888-894. https://doi.org/10.4153/CJM-1968-085-6

[13] H. Hanani, The existence and construction of balanced incomplete block designs, Ann. Math. Statist. 32 (1961) 361-386. https://doi.org/10.1214/aoms/1177705047

[14] D. Hanson, A quick proof that $K_{10} \neq P+P+P$, Discrete Math. 101 (1992) 107-108. https://doi.org/10.1016/0012-365X(92)90595-7

[15] T.P. Kirkman, On a problem in combinatorics, Cambridge Dublin Math. J. 2 (1847) 191-204.

[16] M. Maheo, Strongly graceful graphs, Discrete Math. 29 (1980) 39-46. https://doi.org/10.1016/0012-365X(90)90285-P

[17] M. Meszka, R. Nedela, A. Rosa and M. Škoviera, Decompositions of complete graphs into circulants, Discrete Math. 339 (2016) 2471-2480. https://doi.org/10.1016/j.disc.2016.04.009 
[18] R.C. Read and R.J. Wilson, An Atlas of Graphs (Oxford University Press, Oxford, 1998).

[19] W. Wannasit and S.I. El-Zanati, On free $\alpha$-labelings of cubic bipartite graphs, J. Combin. Math. Combin. Comput. 82 (2012) 269-293.

[20] W. Wannasit and S.I. El-Zanati, On cyclic G-designs where $G$ is a cubic tripartite graph, Discrete Math. 312 (2012) 293-305. https://doi.org/10.1016/j.disc.2011.09.017

Received 4 December 2018

Revised 27 March 2019

Accepted 27 March 2019 